\title{
Correlation between hypoxia Inducible factor-1 alpha (HIF 1 Alpha ) expression with hystopathological level on intracranial meningiomas patients at RSUP Haji Adam Malik Hospital Medan
}

\author{
Victorio $^{1 *}$, Rr Suzy Indharty ${ }^{2}$, Iskandar Japardi² \\ ${ }^{1}$ Neurosurgery Resident of Faculty of Medicine, Universitas Sumatera Utara / Adam \\ Malik General Hospital, Medan, Indonesia \\ ${ }^{2}$ Staff of Department of Neurosurgery Faculty of Medicine Sumatera Utara University/ \\ Adam Malik General Hospital, Medan, Indonesia
}

\begin{abstract}
Background : Meningiomas account for $\pm 30 \%$ of all primary brain and central nervous system tumors and are associated with extremely variable clinical outcomes. Hypoxia plays an important role in the development, angiogenesis and growth of malignant brain tumors. Overexpression of HIF-1 has been demonstrated in many common human cancers and correlated with tumor grading and progression, including renal, colon, and brain tumors .The purpose of this study is to determine the relation between HIF-1 $\alpha$ expression of intracranial meningioma with WHO criteria histopathologically in patients with intracranial men.

Method : This study was a cross sectional analytic study of 32 parts of paraffin block meningioma After staining, then HIF-1 $\alpha$ expression were calculated with light microscope. The results were expressed as the percentage of cells with strong positive staining as follows: $\leq 10 \%$ positive cells- negative $(-)$, between 11 and $50 \%(+)$, and $\geq 51 \%$ positive cells $(++)$.

Result : Based on the results of HIF- $1 \alpha$ Expression examined on 32 intracranial meningioma slides, results found were: in grade I Meningioma there were 13 slides $(30,59 \%)$ included in Expression 0 and 14 slides group (43.75\% in Expression 1+ group, Meningioma grade II obtained 3 slides $(9.37 \%)$ included in the expression of group $1+$, and 1 slides $(3.12 \%)$ belonging to group Expression 2+, While Meningima Grade III was found in 1 slide (3.12\%) included in the group of Expression 2+.

Conclusion : The expression of HIF- $1 \alpha$ in intracranial meningiomas was associated with incidence of recurrency and changes to high grade meningioma (grade 2 and grade 3). This indicates that there is a significant relation between HIF-1 $\alpha$ expression and the degree of meningioma based on WHO classification hystopathologically, correlation value $p=0.044$ ( $p$ $<0.05)$.
\end{abstract}

Keyword : Meningioma, hypoxia Inducible factor-1 alpha, hystopathological level. 


\section{Introduction}

Meningiomas are benign brain tumors derived from brain wrapping tissue or meningens. The most common diagnosed primary brain tumor and $33.8 \%$ of all primary brain tumors. ${ }^{\mathbf{1} \mathbf{2}^{3} \mathbf{3}}$ In the United States, the incidence of meningioma confirmed by pathology examination is estimated at 97.5 per 100,000 inhabitants. However, this number is estimated to be lower than the real due to the presence of some non-surgical meningiomas. While in the UK, the incidence of meningioma is estimated at 5.3 per 100,000 inhabitants and remained stable over the past 12 years ${ }^{\mathbf{1 . 2}}$. Patients with Meningioma have a high life expectancy. Meningioma grades 2 and 3 show varying radiotherapy responses. Thus, there may be other factors affecting the radiotherapy response, such as the condition of tumor cell hypoxia. ${ }^{3}$

Hypoxic conditions in these tumor cells will decrease the response of tumor tissue to radiation therapy because radiation therapy requires good oxygenation. With the presence of oxygen, the radiation sensitivity increases 2.5 - 3 times.

Hypoxia can be detected with a marker of hypoxia tissue Hypoxia Inducible Factor-1 (HIF1). HIF-1 is a transcription factor that plays an important role in maintaining the oxygen balance, both at the cellular level and at the systemic level. HIF-1 $\alpha$ as a marker of hypoxic tissue is detected in most types of solid cancers such as in brain, bladder, breast, bowel, ovarian, pancreatic, kidney, and prostate cancers. Clinically, HIF-1 $\alpha$ overexpression can be used as a marker for diseases in high aggressive conditions and difficult treatment. HIF-1 activates genes that allow tumor cells to survive and thrive in a hypoxic cancer environment

The high expression (overexpression) of HIF-1 $\alpha$ is thought to reduce the sensitivity of meningioma cells to radiation therapy because radiation therapy requires oxygen. Excessive HIF-1 $\alpha$ provides only partial response to radiation therapy. In addition, elevated levels of HIF-1 $\alpha$ in cervical cancer and oropharyngeal cancer are associated with patient survival, where patients expressing HIF-1 $\alpha$ higher have low survival Further studies that analyzed the expression relations of HIF-1 $\alpha$ with therapeutic response, survival and malignancy were necessary to support the statement.

\section{Methodology}

This study was conducted using Cross Sectional analytic study to measure HIF-1 $\alpha$ expression in patients with intracranial meningioma, followed by relationship analysis between HIF-1 $\alpha$ expression with WHO histopathology degree. The study was conducted at Haji Adam Malik Hospital / Faculty of Medicine, Universitas Sumatera Utara, Medan. Sampling of paraffin blocks was conducted in the laboratory room of SMF Anatomical Pathology of RSUP Haji Adam Malik Medan and processed by SMF Anatomical Pathology of RSUP Haji Adam Malik Medan. The study was conducted from June 2015 to June 2016.

Inclusion criteria from this study: Patients who have been clinically diagnosed with meningioma at various intracranial sites, and Patients who have performed surgery so that there is a network of tumors that can be confirmed as meningioma by the Anatomical Pathology section. While the exclusion criteria of this study were patients who experienced recurrence (recurrence) or recurrence (residif), Patients who experienced trauma, and Patients who have other tumors on the body.

Examination of HIF-1 $\alpha$ expression on Intracacranial Meningioma immunohistochemically gives results: $0=$ No dyeing at all or very little staining / partial cell nucleus less than $10 \%$ of tumor cells $1+=$ Intensity weak staining of the colored intisel brownish red that can be observed between $11 \%-50 \%$ of tumor cells. $2+=$ Medium Color Intensity at the intisel that becomes a brownish red color that can be observed in over $51 \%$ of tumor cells

\section{Result}

\section{Gender Distribution}

After data collection and frequency distribution analysis were obtained, female sex samples were higher than male samples, in which female samples were 25 people $(78.1 \%)$ and men 7 people $(21.9 \%)$. 
Table .1. Sex Distribution

\begin{tabular}{|c|c|c|}
\hline & $\mathbf{N}$ & $\mathbf{\%}$ \\
\hline Male & 7 & 21,9 \\
\hline Female & 25 & 78,1 \\
\hline Total & 32 & 100,0 \\
\hline
\end{tabular}

\section{Age Distribution}

After a descriptive analysis of age, we found that mean value of the age was 44.5 years with a minimum value of 32 years and a maximum of 60 years. The median value was 43.5 years. Against the sample, the age of intracranial meningioma occurred in the age of 30-39 years old, 40-49 years old and 50-59 years old, with 10 patients $(31,3 \%), 13$ patients $(40.6 \%), 7$ patients $(21.9 \%)$.

Table 2. Age Distribution (Year)

\begin{tabular}{|c|c|c|}
\hline & \multicolumn{2}{|c|}{ Nilai } \\
\hline Mean & \multicolumn{2}{|c|}{44,5625} \\
\hline Median & \multicolumn{2}{|c|}{43,5000} \\
\hline Std. Deviation & \multicolumn{2}{|c|}{8,58708} \\
\hline Minimum & \multicolumn{2}{|c|}{32,00} \\
\hline Maximum & \multicolumn{2}{|c|}{60,00} \\
\hline Age Group & $\mathrm{N}$ & $\%$ \\
\hline & & \\
\hline $30-39$ & 10 & 31,3 \\
\hline $40-49$ & 13 & 40,6 \\
\hline $50-59$ & 7 & 21,9 \\
\hline $60-69$ & 2 & 6,3 \\
\hline & & \\
\hline Total & 32 & 100 \\
\hline
\end{tabular}

\section{Distribution Based on Histopathology}

Based on histopathology results, the highest frequency was found in Meningothelial meningioma type of 15 cases (46.9\%), followed by Fibroblastic meningioma 7 cases (21.9\%), Atypical meningioma 2 cases (6.3\%), ClearCell Meningioma 2 cases ( 6.3\%), Transtitional Meningioma 2 Cases (6.3\%), Metaplastic meningioma 2 Cases (6.3\%), Malignant meningioma 1 Case (3.1\%), Psromous meningioma 1 case (3.1\%),

Table .3. Histopatholgy Distribution

\begin{tabular}{|c|c|c|}
\hline Histopathology & $\mathbf{N}$ & $\mathbf{\%}$ \\
\hline Meningothelial & 15 & 46,9 \\
\hline Transitional & 2 & 6,3 \\
\hline Fibroblastic & 7 & 21,9 \\
\hline Clear Cell & 2 & 6,3 \\
\hline Atypical & 2 & 6,3 \\
\hline Malignant & 1 & 3,1 \\
\hline Metaplastic & 2 & 6,3 \\
\hline Psammomatous & 1 & 3,1 \\
\hline
\end{tabular}




\begin{tabular}{|c|c|c|}
\hline Histopathology & $\mathbf{N}$ & $\mathbf{\%}$ \\
\hline Meningothelial & 15 & 46,9 \\
\hline Transitional & 2 & 6,3 \\
\hline Fibroblastic & 7 & 21,9 \\
\hline Clear Cell & 2 & 6,3 \\
\hline Atypical & 2 & 6,3 \\
\hline Malignant & 1 & 3,1 \\
\hline Metaplastic & 2 & 6,3 \\
\hline Psammomatous & 1 & 3,1 \\
\hline Total & 32 & 100.0 \\
\hline
\end{tabular}

\section{Frequency Distribution of Meningioma According to WHO Classification}

Based on WHO classification, meningioma distribution was obtained as follows, patients with WHO grade 1 meningioma 27 patients (84.4\%), WHO grade 2 are 4 patients (12.5\%) and 1 WHO grade $3(3.1 \%)$.

Table 4. WHO Grading Distribution

\begin{tabular}{|c|c|c|}
\hline Histopathology & N & \% \\
\hline WHO Grade 1 & 27 & 84,4 \\
\hline WHO Grade 2 & 4 & 12,5 \\
\hline WHO Grade 3 & 1 & 3,1 \\
\hline Total & 32 & 100.0 \\
\hline
\end{tabular}

\section{HIF-1a Expression Distribution}

The expression of HIF- $1 \alpha$ was obtained by assessing HIF-1 $\alpha$ expression on a preparation using a Light microscope. Results of HIF-1 $\alpha$ Expression were obtained in all study samples.

Table 5. Distributio of HIF-1 a Expression

\begin{tabular}{|c|c|c|}
\hline Expression & $\mathbf{N}$ & \% \\
\hline 0 & 14 & 43,8 \\
\hline $1+$ & 16 & 50,0 \\
\hline $2+$ & 2 & 6,3 \\
\hline Total & 32 & 100.0 \\
\hline
\end{tabular}

\section{HIF-1 $\alpha$ Expression Distribution in Intracranial Meningioma Based on WHO Grade}

Expression of HIF-1 $\alpha$ by WHO Grade, HIF-1 $\alpha$ Expression Result of group 0, Group 1+ and Group 2+. 
Table 6 HIF-1 $\alpha$ Expression Distribution in Intracranial Meningioma Based on WHO Grade

\begin{tabular}{|c|c|c|c|}
\hline Histopathology & 0 & $1+$ & $2+$ \\
\hline WHO Grade 1 & 13 & 14 & - \\
\hline WHO Grade 2 & - & 3 & 1 \\
\hline WHO Grade 3 & - & - & 1 \\
\hline Total & 13 & 17 & 2100 \\
\hline
\end{tabular}

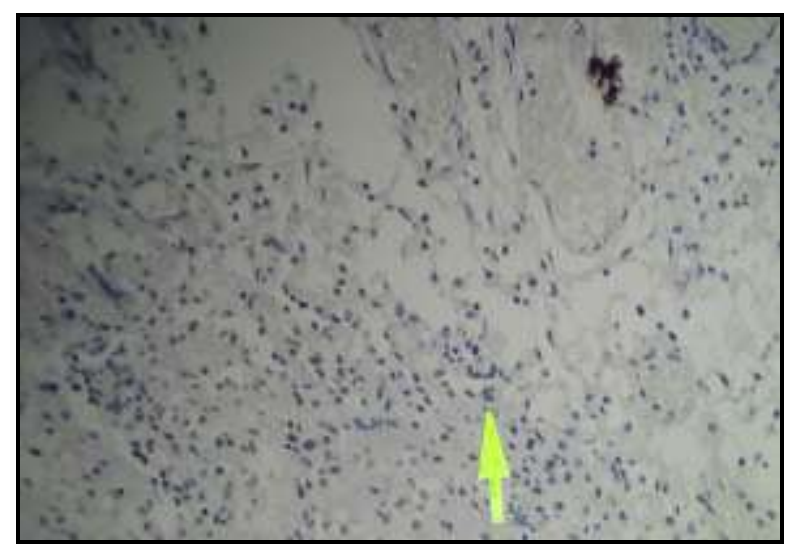

Picture.1 0: No dyeing at all or very little staining / partial cell nucleus less than $10 \%$ of tumor cells

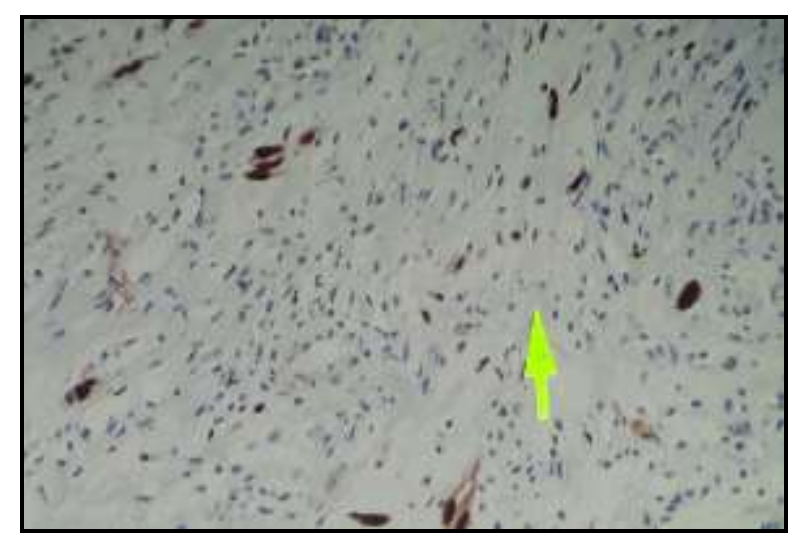

Picture 2 1+: Intensity weak staining of the colored intisel brownish red that can be observed between $11 \%-50 \%$ of tumor cells

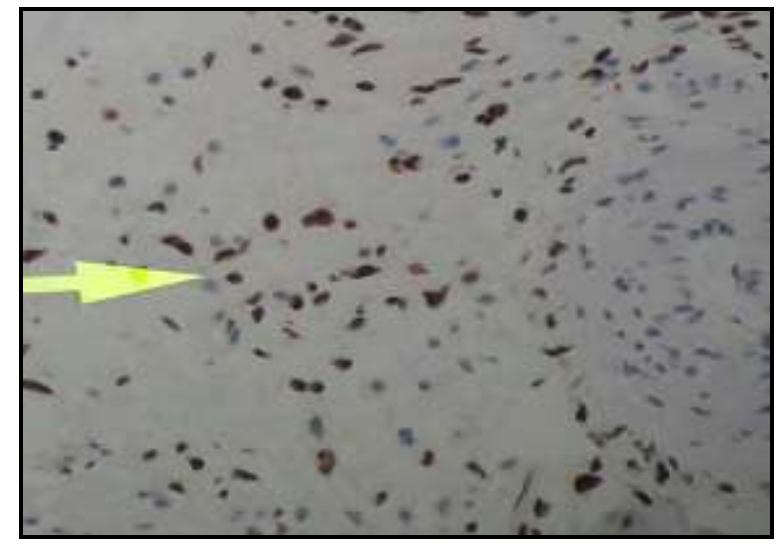

Picture 3 2+: Medium Color Intensity at the intisel that becomes a brownish red color that can be observed in over $51 \%$ of tumor cells 


\section{Distribution of Relations Between HIF-1a Expression Against Histopathological Degrees Intracranial Meningioma}

After a review of the data obtained, we will look for the relationship between HIF-1 $\alpha$ Expression Against Histopathology Degree of Intracranial Meningioma. The analysis will be performed using Spearman's rho test.

\begin{tabular}{|c|c|c|c|c|}
\hline \multicolumn{5}{|l|}{ Correlations } \\
\hline & & & hasil_grade & Hasil \\
\hline \multirow[t]{6}{*}{ Spearman's rho } & \multirow[t]{3}{*}{ hasil_grade } & $\begin{array}{l}\text { Correlation } \\
\text { Coefficient }\end{array}$ & 1,000 &, $359^{*}$ \\
\hline & & Sig. (2-tailed) & & $\begin{array}{ll}0 & 4\end{array}$ \\
\hline & & $\mathrm{N}$ & 32 & 32 \\
\hline & \multirow[t]{3}{*}{ Hasil } & $\begin{array}{l}\text { Correlation } \\
\text { Coefficient }\end{array}$ &, $359^{*}$ & 1,000 \\
\hline & & Sig. (2-tailed & ,044 & . \\
\hline & & $\mathrm{N}$ & 32 & 32 \\
\hline
\end{tabular}

Based on the table above, the correlation value obtained relationship between Expression and histopathology with $p=0.044$ ( $p<0.05$ ). This suggests that the correlation between HIF-1 $\alpha$ Expression and Histopathology based on WHO grade is significant. Spearman Correlation value of 0.359 indicates that the direction of positive correlation with weak correlation strength.

\section{Discussion}

In this study, it was found that from 32 samples of patients with intracranial meningioma who went to RSUP H Adam Malik Medan June 2015 - June 2016 period. Of the 32 samples, 25 samples (78.1\%) female and 7 samples $(21.9 \%)$ are man. When comparisons of both sexes are obtained the comparison is; women: men equal to $3.56: 1$. Other case with epidemiological studies showing that dominant meningiomas occur in women than men with a ratio of about 2.5: 1 (Landriel, 2012)

Sample Age's are in the range of 40-49 years (40.6\%). This age range is a productive age range where sex hormone levels are higher in this age range. Result of descriptive analysis found that mean value is 44,6 year with minimum value 32 years and maximum 60 year. The median value was 43.5 years.

Based on histopathology results, the highest frequency was found in meningothelial meningioma type of 15 cases (46.9\%), followed by Fibroblastic meningioma 7 cases (21.9\%), Transitional meningioma, Atypical meningioma, Clear Cells meningioma, Metaplastic meningioma for 2 cases 6.3\%). The rest was followed by Psammomatous, Anaplastic and Metaplastic meningioma of 1 case (3.1\%).

According to the WHO classification, the distribution of patients with WHO grade 1 meningioma was 26 patients $(81.3 \%)$, WHO grade 2, 4 patients (12.5\%) and 1 WHO grade $3(6.3 \%)$. Based on the results of HIF$1 \alpha$ Expression Examination on 32 intracranial meningioma preparations, the results were found: in Grade I Menomasoma there were 13 preparations (30,59\%) included in Expression 0 and 14 Preparation group (43.75\% belonging to Expression 1+ group, Meningioma Grade II obtained 3 preparations (9.37\%) included in the expression group 1+, and 1 Preparatory (3.12\%) belonging to Expression 2+ group, While in Meningima Grade III found 1 Preparatory (3.12\%) which is included in the 2+ Expression group.

Based on a study conducted by Joanna et al in 2013 at the Department of Neurosurgery of the University of Bialystok, Poland, it was found that in 104 samples of patients with Grade 1 meningioma they were diagnosed with 58 patients resulted in negative expression of 46 cases $(44.2 \%)$, positive one (1+) 56 cases (53.8\%), and Positive two (2+). In 50 patients with grade 2 and grade 3 meningiomas found negative expression

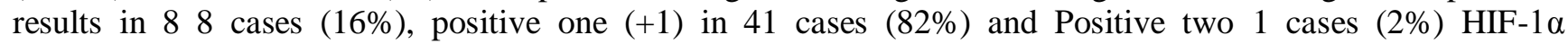


expression was found in all grade 1 meningiomas, who had recurrences and changed to High grade Meningioma. ${ }^{10} 11$

This means that based on the results of this study compared with some previous studies there are some significant similarities of results that HIF- $1 \alpha$ expression in meningioma associated with recurrence incidence and changes to high grade meningioma (grade 2 and grade 3 )

To see whether HIF-1 $\alpha$ Expression also plays a role in the subtype of meningioma, Spearman's rho tested HIF-1 $\alpha$ expression. There was a correlation value of $p=0,026(p<0,05)$ obtained on expression of HIF$1 \alpha$ relationship with histopathology degree of intracranial meningioma. This shows that there is a significant relationship between HIF-1 $\alpha$ expression and histopathologic degree of intracranial meningioma. Spearman Correlation value of 0.393 indicates that the direction of positive correlation with weak correlation strength. As a limitation of this research is the data used is not homogeneous and not normally distributed.

Research on HIF-1 $\alpha$ Expression Relation with intracranial meningioma histopatholgy degree has not been done by other researchers, especially in North Sumatra. In this study based on data analysis using Spearman correlation test showed that there is a positive correlation with weak correlation strength. This shows that there is a significant association between HIF-1 $\alpha$ expression and histopathology of patients with intracranial meningioma.

\section{Conclusion}

In this study, there were 32 samples of intracranial meningioma patients who went to RSUP H Adam Malik Medan from June 2015 to June 2016. Of the 32 samples, 25 samples (78.12\%) of women and 7 samples (21.87\% men. When comparisons of both sexes are obtained the comparison is; women: men equal to 3.56: 1 . Average in the 40-49 years age range (40.625\%). Based on histopathologic results, the highest frequency was found in Meningothelial meningioma type of 15 cases (46.875\%), followed by Fibroblastic meningioma 7 cases (21.1\%), Transitional meningioma, Atypical meningioma, Clear Cells meningioma, Metaplastic meningioma for 2 cases $(6,25 \%)$. The rest was followed by Psammomatous, Anaplastic and Metaplastic meningioma of 1 case $(3.125 \%)$.

Based on WHO classification, meningioma distribution was obtained as follows, patients with WHO grade 1 meningioma 27 patients $(84.4 \%)$, WHO grade 2 for 4 patients $(12.5 \%)$ and 1 WHO grade $3(3.1 \%)$. Based on the results of HIF- $1 \alpha$ Expression Examination on 32 intracranial meningioma preparations, the results were found: in Grade I Menomasoma there were 13 preparations (30,59\%) included in Expression 0 and 14 Preparation group (43.75\% belonging to Expression 1+ group, Meningioma Grade II obtained 3 preparations (9.37\%) included in the expression group 1+, and 1 Preparatory (3.12\%) belonging to Expression 2+ group, While in Meningima Grade III found 1 Preparatory (3.12\%) which is included in the Expression 2+ group.This means that HIF-1 $\alpha$ expression in meningioma is associated with recurrence incidence and changes to high grade meningioma (grade 2 and grade 3) .This shows that there is a significant relationship between HIF-1 $\alpha$ expression and degree of meningioma based on WHO classification, with correlation value $p=0,044(p<0,05)$.

\section{References}

1. Fisher, J. L., Schwartzbaum, J. A., Wrensch, M., \& Wiemels, J. L. (2007). Epidemiology of Brain Tumors. Neurologic Clinics, 25(4), 867-890. doi:10.1016/j.ncl.2007.07.002.

2. Al-Mefty, O., Abdulrauf, S. I., \& Haddad, G. F. 2011. Meningioma. In Youmans Neurological Surgery, Winn HR (ed), 6thed. New York: Elsevier. pp. 1426-1449.

3. Cea-Soriano, L., Wallander, M.-A., \& García Rodríguez, L. A. (2012). Epidemiology of meningioma in the United Kingdom. Neuroepidemiology, 39(1), 27-34. doi:10.1159/000338081.

4. Giatromanolaki, A., \& Harris, A. L. (2006). Tumour hypoxia, hypoxia signalling pathways and hypoxia inducible factor expression in human cancer. Anticancer Research, 21(6B), 4317-4324.

5. Harris, A. L. (2001). Hypoxia - a key regulatory factor in tumor growth. Nature Reviews. Cancer, 2006(2), 38-46. 
6. Janet, L. Jensen R Predicting outcomes of patients with intrakranial meningiomas using molecular markers of Hypoxia, Vascularity and Proliferation, Department of Neurosurgery, Huntsman Cancer Institute, University of Utah, 2012

7. Landriel, F., \& Black, P. 2012. Meningiomas. In: Ellenbogen, R., Abdulrauf, S., Sekhar, L., Principles of Neurological Surgery. Edition 3. New York: Saunders 3. Lee JW, Bae SH, Jeong JW, Kim SH, Kim KW. Hypoxia-inducible factor (HIF-1) $\alpha$ : its protein stability and biological functions, Experimental and Molecular Medicine, 2004; 36(1):1-12.

8. Iskandar Japardi, (2015). Buku Teks book Komprehensif Meningioma, Indo Karya adv, 627-643

9. Novi, S., \& Sadikin, M. Septelia, Ekspresi Relatif mRNA Hypoxia Inducible Factor 1 Alpha pada sel glioma penderita, Departemen Of Biochemistry and molecular Biology, FKUI 2012

10. Reszec Joana, Ruthkowsky R., (2013). The Expression of Hypoxia Inducible factor -1 in primary brain tumor, International Journal of Neuroscience, 657-662.

11. Reszec Joana, R, Ruthkowsky R., (2013). Evaluation of mast cells and Hypoxia inducible factor 1 expression in meningiomas of various grades in correlation with peritumoral brain edema, Journal of Neurooncology.

12. Sang, N., Stiehl, D. P., Bohensky, J., Leshchinsky, I., Srinivas, V., \& Caro, J. (2003). MAPK signaling up-regulates the activity of hypoxia-inducible factors by its effects on p300. The Journal of Biological Chemistry, 278(16), 14013-14019. doi:10.1074/jbc.M209702200.

13. Rockhill, J., Mrugala, M., \& Chamberlain, M. C. (2007). Intrakranial Meningiomas: an Overview of Diagnosis and Treatment. Neurosurgical Focus, 23(4), 1-7. doi:10.3171/FOC-07/10/E1.

14. Semenza, G. L. (2000). HIF-1: mediator of physiological and pathophysiological response to hypoxia. Journal of Applied Physiology, 88(4), 1474-1480. doi:10.1152/jappl.2000.88.4.1474. 